\title{
Predictive value of chest HRCT for survival in idiopathic pulmonary arterial hypertension
}

\author{
Aneta Kacprzak ${ }^{1 *}$, Barbara Burakowska², Marcin Kurzyna ${ }^{3}$, Anna Fijałkowska ${ }^{4}$, Michał Florczyk ${ }^{3}$, \\ Maria Wieteska-Miłek ${ }^{3}$, Szymon Darocha ${ }^{3}$, Adam Torbicki ${ }^{3}$ and Monika Szturmowicz
}

\begin{abstract}
Background: Little attention has been paid to chest high resolution computed tomography (HRCT) findings in idiopathic pulmonary arterial hypertension (IPAH) patients so far, while a couple of small studies suggested that presence of centrilobular ground-glass opacifications (GGO) on lung scans could have a significant negative prognostic value. Therefore, the aims of the present study were: to assess frequency and clinical significance of GGO in IPAH, and to verify if it carries an add-on prognostic value in reference to multidimensional risk assessment tool recommended by the 2015 European pulmonary hypertension guidelines.
\end{abstract}

Methods: Chest HRCT scans of 110 IPAH patients were retrospectively analysed. Patients were divided into three groups: with panlobular (p)GGO, centrilobular (c) GGO, and normal lung pattern. Association of different $G G O$ patterns with demographic, functional, haemodynamic, and biochemical parameters was tested. Survival analysis was also performed.

Results: GGO were found in 46\% of the IPAH patients: pGGO in 24\% and cGGO in 22\%. Independent predictors of pGGO were: positive history of haemoptysis, higher number of low-risk factors, and lower cardiac output. Independent predictors of CGGO were: positive history of haemoptysis, younger age, higher right atrial pressure, and higher mixed venous blood oxygen saturation. CGGO had a negative prognostic value for outcome in a 2-year perspective. This effect was not seen in the longer term, probably due to short survival of cGGO patients.

Conclusions: Lung HRCT carries a significant independent prognostic information in IPAH, and in patients with cGGO present on the scans an early referral to lung transplantation centres should be considered.

Keywords: Idiopathic pulmonary arterial hypertension, High resolution computed tomography, Ground-glass opacifications, Survival, Risk factors

\section{Introduction}

Pulmonary hypertension $(\mathrm{PH})$ is defined as an increase in mean pulmonary artery pressure (PAPm) $\geq 25 \mathrm{mmHg}$ at rest as assessed by right heart catheterisation (RHC) [1]; recently threshold of $20 \mathrm{mmHg}$ has been proposed [2]. There are multiple clinical conditions associated with $\mathrm{PH}$, and the classification of $\mathrm{PH}$ was created based

${ }^{*}$ Correspondence: ankac2000@yahoo.com

1 1st Department of Lung Diseases, National Tuberculosis and Lung Diseases Institute, Płocka 26, 01-138 Warsaw, Poland

Full list of author information is available at the end of the article on similarities in their pathophysiological mechanisms, clinical presentation, haemodynamic characteristics, and therapeutic management $[1,2]$. There are five main groups of PH: 1. pulmonary arterial hypertension (PAH), 2. PH due to left heart diseases, 3 . PH due to lung diseases and/or hypoxia, 4. PH due to pulmonary artery obstructions, 5. PH with unclear and/or multifactorial mechanisms. Each group is further divided into subgroups $[1,2]$. Group 1, i.e. PAH, results primarily from pulmonary vascular disease involving pulmonary arteries, arterioles, capillaries and small veins. Vasoconstriction and remodelling of pulmonary vessels cause rise in original author(s) and the source, provide a link to the Creative Commons licence, and indicate if changes were made. The images or other third party material in this article are included in the article's Creative Commons licence, unless indicated otherwise in a credit line to the material. If material is not included in the article's Creative Commons licence and your intended use is not permitted by statutory regulation or exceeds the permitted use, you will need to obtain permission directly from the copyright holder. To view a copy of this licence, visit http://creativecommons.org/licenses/by/4.0/. The Creative Commons Public Domain Dedication waiver (http://creativeco mmons.org/publicdomain/zero/1.0/) applies to the data made available in this article, unless otherwise stated in a credit line to the data. 
pulmonary vascular resistance (PVR), which in turn leads to increase in PAP, and finally adversely affects performance and structure of the right heart ventricle causing its failure [1]. PAH belongs to pre-capillary $\mathrm{PH}$ category and haemodynamic definition corresponding with it includes: PAPm $\geq 25 \mathrm{mmHg}$, pulmonary artery wedge pressure $(\mathrm{PAWP}) \leq 15 \mathrm{mmHg}, \mathrm{PVR} \geq 3$ Wood Units [1]. $\mathrm{PAH}$ group encompasses following subtypes: idiopathic (I) $\mathrm{PAH}$, heritable $(\mathrm{H}) \mathrm{PAH}$, drug- and toxin-induced $\mathrm{PAH}$, $\mathrm{PAH}$ associated with: connective tissue disease, human immunodeficiency virus (HIV) infections, portal hypertension, congenital heart disease, or schistosomiasis, PAH long-term responders to calcium channel blockers, PAH with overt features of venous/capillaries involvement, and finally persistent $\mathrm{PH}$ of the newborn syndrome $[1,2]$. IPAH is diagnosed in cases without any family history of $\mathrm{PH}$ or known triggering factor [1]. HPAH occurs in a familial context due to mutations in PAH predisposing genes, most frequently in bone morphogenetic protein receptor 2 (BMPR2) gene [1]. There are no significant differences between IPAH and HPAH in terms of clinical, radiological, and haemodynamic presentation, the disease course, management or prognosis. PAH with overt features of venous/capillaries involvement includes pulmonary veno-occlusive disease (PVOD) and pulmonary capillary haemangiomatosis ( $\mathrm{PCH})$. In $\mathrm{PVOD} / \mathrm{PCH}$ venous and capillary involvement is more prominent than in other PAH forms. PVOD/PCH may be idiopathic, heritable, induced by drugs, toxins, and radiation, or it can complicate the course of connective tissue disease and HIV infection [1]. More pronounced pulmonary venous/capillary involvement is associated with a poor prognosis, a limited response to PAH therapy and a risk of pulmonary oedema with these treatments $[1,3-5]$. Ultimate distinction between PVOD/PCH and I/HPAH can be made only on histopathologic or genetic basis [1]. The former can be applied only either post-mortem or in cases of lung transplantation (LTx) because lung biopsy is contraindicated in $\mathrm{PH}$. The latter requires confirmation of biallelic mutations in the eukaryotic translation initiation factor 2alpha kinase 4 (EIF1AK4) gene - present in all patients with heritable form of $\mathrm{PVOD} / \mathrm{PCH}$ and in about $25 \%$ of sporadic cases $[1,5]$. However, the diagnosis may be strongly suspected in PAH cases with very low lung diffusion capacity for carbon monoxide (DLCO), resting hypoxemia, severe exertional desaturation, pulmonary oedema in response to PAH therapy, and the characteristic triad of findings on chest high resolution computed tomography (HRCT): centrilobular ground-glass opacities, mediastinal lymphadenopathy, and smooth thickening of the interlobular septa [1, 3-6]. Normal chest HRCT doesn't exclude PVOD/PCH, though $[3,5]$.
Ground-glass opacities (GGO) is a radiological term for areas of hazy increased lung parenchyma density not sufficient to obscure bronchial and vascular margins on chest HRCT [7]. They are non-specific findings, and there are two patterns of GGO distribution: centrilobular (cGGO) and panlobular (pGGO) [7, 8]. CGGO, also called centrilobular nodules, are related to centrilobular core structures such as arterioles, bronchioles, a surrounding lymphatic network, and supporting connective tissue. On HRCT scans centrilobular nodules may have focal, multifocal, or diffuse appearance. CGGO correspond to various types of histological pictures depending on disease entity [8]. PGGO usually reflect affection of the air space, interstitium, or both these compartments; it can be caused by alveolar or interstitial oedema, an inflammatory process or alveolar haemorrhage [7-9]. In IPAH, lung scans are expected to display no significant abnormalities that would suggest underling respiratory disease [1]. On the other hand, it is now well recognised that up to $50 \%$ of PAH patients may present GGO on HRCT scans despite not having any airway or lung parenchymal disease $[1,3,6$, 10-17]. CGGO were seen in $23-28 \%$ of patients with $\mathrm{I} / \mathrm{H} /$ anorexigen-induced $\mathrm{PAH}$, with no signs of PVOD/ $\mathrm{PCH}$ on lung pathologic evaluation $[3,6,15]$.

IPAH remains a life-threatening disease despite constant development of therapeutic options and improved management plans [1, 18-24]. Current medical therapies aim to overcome imbalance between vasoactive and vasodilator mediators and restore the endothelial cell function in pulmonary arterial bed, as these elements play essential role in pulmonary vascular remodelling in PAH. PAH-specific medications include: prostacyclin analogues and receptor agonists, phosphodiesterase 5 inhibitors, endothelin-receptor antagonists, and cyclic guanosine monophosphate activators $[1,25]$. The ultimate cure for advanced IPAH is LTx [1], but the procedure carries a significant risk of severe complications and death [26]. Therefore, a referral for LTx requires a careful consideration of risks and benefits. Referral timing should be based on a patient's individual survival prognosis and expected waiting time on local transplant list $[1,27,28]$. There are few risk stratification tools, such as REVEAL score [29] and European Society of Cardiology (ESC)/European Respiratory Society (ERS) strategy [1], recommended for prognosis assessment $[1,28]$. Still, many IPAH patients die being referred for LTx too late or not at all [18-23, 30, 31]. Neither REVEAL score nor ESC/ERS risk assessment tool incorporates findings of chest HRCT, while presence of cGGO on the lung scans has been reported to have a significant prognostic value for outcome in IPAH patients in few studies [11, 12]. 
Although well appreciated, the phenomenon of inhomogeneous lung attenuation in IPAH has not been thoroughly investigated and described. Consequently, the objectives of our study were: to assess frequency and clinical significance of GGO in IPAH, and to verify if it carries an add-on prognostic value in reference to ESC/ ERS multidimensional risk assessment tool.

\section{Method}

Patients diagnosed with IPAH in our hospital between 1997 and 2011, and for whom chest HRCT scans were available for review, were retrospectively analysed. Diagnosis of IPAH was based on evidence of PAH on RHC and exclusion of known causes of $\mathrm{PH}$. All included patients had PAPm $\geq 25 \mathrm{mmHg}$, PAWP $\leq 15 \mathrm{mmHg}$, and PVR $>3$ Wood units [1]. All patients underwent broad differential workup of PH. It included anamnesis covering personal and familial medical history, exposure to drugs and toxins, as well as physical examination findings and additional tests. Left heart diseases and congenital heart diseases were excluded with means of echocardiography and RHC (normal PAWP), lung diseases were excluded on the basis of pulmonary function testing and HRCT scanning, pulmonary artery obstruction was excluded with pulmonary artery contrast enhanced CT and perfusion lung scintigraphy. All patients had connective tissue disease ruled out, negative testing for HIV infection, and negative abdominal ultrasound for portal hypertension. Two of included patients had unclear familial history of $\mathrm{PH}$. The studied group did not contain patients with high clinical suspicion of PVOD/PCH, i.e. patients with a characteristic triad of chest HRCT findings, or patients who developed pulmonary congestion in response to vasodilators. However, no histopathologic verification or genetic testing were performed, so the cohort could include patients with HPAH or PAH in the course of PVOD/PCH.

The HRCT examinations were performed between Jan 1997 and Nov 2011, with use of either a single-row helical unit Picker PQ 2000 (Siemens) or a multi-row Somatom Sensation 16 (Siemens). In part of the patients images were obtained with a sequential acquisition technique with $1-\mathrm{mm}$ section thickness at $10 \mathrm{~mm}$ intervals, in others high resolution images were reconstructed from contrast enhanced spiral acquisition. All scans were acquired in the supine position, at end-inspiration. There were no differences in the radiological protocols between studies obtained with both CT equipments, and differences in technical specifications of both units made no impact on assessment of elements included in the analysis. The images were reassessed by the radiologist experienced both in $\mathrm{PH}$ and interstitial lung diseases, blinded to patients' clinical details and outcomes. The main focus was on assessment of lung parenchyma homogeneity, and patients were divided into three groups: with cGGO pattern, with pGGO pattern, and with normal pattern. CGGO were further evaluated as distributed evenly or with a zonal predominance, pGGO as patchy or perihilar. Mediastinal lymphadenopathy (smallest diameter $>10 \mathrm{~mm}$ ) and smooth thickening of interlobular septa were also recorded.

Data collected for analyses were: sex, age at the time of chest HRCT, cigarette smoking status, history of haemoptysis, presence of patent foramen ovale, World Health Organisation functional class (WHO FC), 6-min walking test results (distance, pre-test and the lowest exertional oxygen saturation measured with pulse oximeter), plasma N-terminal pro-brain natriuretic peptide (NTproBNP), DLCO percent of predicted value (\%pred), haemodynamic parameters: mean right atrial pressure (RAPm), systolic, diastolic and mean pulmonary artery pressures, cardiac output $(\mathrm{CO})$ and cardiac index $(\mathrm{CI})$, mixed venous blood oxygen saturation $\left(\mathrm{Svo}_{2}\right)$, PVR [32], result of acute vasoreactivity testing (responder or nonresponder according to ESC/ERS guidelines definition [1]). Median (IQR) interval between chest HRCT and RHC was 10 (3-74) days. All other risk factors were assessed simultaneously, i.e. during the same hospitalisation, with chest HRCT scanning.

For risk stratification 6 of 13 risk factors recommended in the 2015 ESC/ERS PH guidelines were used: WHO FC, 6-min walking test distance (6MWD), NT-proBNP plasma level, RAPm, CI, and $\mathrm{SvO}_{2}$, with cut-off values and three levels of risk as proposed in the document [1]. The method to calculate each patient's risk was adopted from Kylhammar et al. [22]. The French approach based on number of low-risk factors was also applied [21].

The STATISTICA v. 13 (Statsoft) computer software was used for statistical analysis. Continues data were presented as median with interquartile range, and Kruskal-Wallis' or U Mann-Whitney's tests were used for comparison between three or two groups, respectively. Categorical variables were shown as actual number with percentage where appropriate, and the Pearson's chi-square test was used for comparison between groups. Logistic regression was performed to determine factors associated with different HRCT patterns, the normal pattern was a reference class. The Somers' D was used to built the multivariate regression models. Transplantfree survival was calculated from the date of chest HRCT scanning to the date of death or LTx (complete observation) or the date of last follow-up, with 23rd Apr 2020 terminating the period of observation. Survival analysis was performed using the Kaplan-Meier method. Survival between groups was compared with log-rank test. Univariable and multivariable Cox proportional hazards 
models were used to evaluate the predictive value of the HRCT patterns as well as the other analysed variables. Parameters with $\mathrm{p}<0.2$ in the univariate analysis were included in the multivariate analysis. Hazard ratios (HR) with $95 \%$ confidence interval $(95 \% \mathrm{CI})$ were presented. $\mathrm{P}<0.05$ was considered statistically significant.

No ethics committee approval or informed consent were required due to retrospective character of this study. It was conducted in agreement with the Declaration of Helsinki and the European General Data Protection Regulation.

\section{Results}

\section{General characteristics and chest HRCT findings}

The studied group consisted of 110 IPAH patients: 102 (93\%) incident, 80 (73\%) women, age median value was 44.3 years (range $17.3-78.5$ years). Fifty (46\%) patients had the abnormal lung pattern on HRCT scans. The
pGGO were found in 26 (24\%) patients, perihilar localisation was seen in $50 \%$ of them. The cGGO were found in $24(22 \%)$ patients, nodules were widespread and with no specific zonal predominance in all cases. The remaining $54 \%$ of the patients were classified as normal HRCT pattern. One patient with pGGO had lymphadenopathy and septal thickening. Among patients with cGGO, two had lymphadenopathy, and another one had septal thickening. Three patients with normal pattern had lymphadenopathy. The characteristics of the whole studied group, as well as detailed comparison of the three groups according to the lung HRCT pattern are presented in Tables 1 and 2, GGO patterns are shown in Fig. 1.

The abnormal HRCT pattern was more frequent in women (29\% had pGGO, 25\% cGGO, and $49 \%$ normal pattern) than in man (10\% had pGGO, $13 \%$ cGGO, and $77 \%$ normal pattern), $\mathrm{p}=0.004$. Patients with abnormal pattern had lower median age: 37.5

Table 1 Demographic, functional and biochemical parameters for the whole group and according to the HRCT pattern

\begin{tabular}{|c|c|c|c|c|c|c|c|c|c|}
\hline & \multicolumn{2}{|c|}{ All patients } & \multicolumn{2}{|c|}{ cGGO pattern } & \multicolumn{2}{|c|}{ pGGO pattern } & \multicolumn{2}{|c|}{ Normal pattern } & \multirow[t]{2}{*}{$p$ value* } \\
\hline & $\mathbf{N}$ & $\begin{array}{l}\text { Median (IQR) or } \\
\mathrm{N}(\%)\end{array}$ & $\mathbf{N}$ & $\begin{array}{l}\text { Median (IQR) or } \\
\mathrm{N}(\%)\end{array}$ & $\mathbf{N}$ & $\begin{array}{l}\text { Median (IQR) or } \\
\mathrm{N}(\%)\end{array}$ & $\mathbf{N}$ & $\begin{array}{l}\text { Median (IQR) or } \\
\mathrm{N}(\%)\end{array}$ & \\
\hline Age [years] & 110 & $44.3(30.0-56.6)$ & 24 & $32.1(24.3-49.0)$ & 26 & $44(27-49.6)$ & 60 & $46.8(37.6-59.0)$ & 0.064 \\
\hline Age $<40$ years & 110 & $44(40)$ & 24 & $15(63)$ & 26 & $12(46)$ & 60 & $17(28)$ & 0.012 \\
\hline Sex female:male & 110 & $80: 30(73: 27)$ & 24 & $20: 4(83: 17)$ & 26 & $23: 3(88: 12)$ & 60 & $37: 23$ (62:38) & 0.016 \\
\hline Ever-smokers & 106 & 41 (39) & 21 & $9(43)$ & 26 & $5(19)$ & 59 & $27(46)$ & 0.062 \\
\hline $\begin{array}{l}\text { Positive history of } \\
\text { haemoptysis }\end{array}$ & 108 & $18(16)$ & 24 & 7 (29) & 26 & $6(23)$ & 58 & $5(9)$ & 0.046 \\
\hline PFO & 93 & $29(31)$ & 22 & $7(32)$ & 20 & $8(40)$ & 59 & $14(27)$ & 0.59 \\
\hline WHO FC: & 107 & & 24 & & 26 & & 57 & & 0.14 \\
\hline 1 & & 0 & & 0 & & 0 & & 0 & \\
\hline 2 & & $57(53)$ & & $14(58)$ & & $17(65)$ & & $26(46)$ & \\
\hline 3 & & $44(41)$ & & $7(29)$ & & $8(31)$ & & $29(51)$ & \\
\hline 4 & & $6(6)$ & & $3(13)$ & & $1(4)$ & & $2(4)$ & \\
\hline DLCO [\%pred] & 84 & $66.8(52.8-76.5)$ & 15 & 58.7 (33.4-71.6) & 21 & 70.6 (60.4-73.6) & 48 & $66.7(39.0-83.1)$ & 0.27 \\
\hline $6 \mathrm{MWD}[\mathrm{m}]$ & 105 & $396(318-474)$ & 21 & 436 (380-484) & 26 & $415.5(380-484)$ & 58 & $379.5(298.0-450.0)$ & 0.06 \\
\hline 6MWD risk group: & 105 & & 21 & & 26 & & 58 & & 0.34 \\
\hline Low & & $37(35)$ & & $10(48)$ & & $11(42)$ & & $16(28)$ & \\
\hline Intermediate & & $63(60)$ & & $11(52)$ & & $14(54)$ & & $38(66)$ & \\
\hline High & & $5(5)$ & & $0(0)$ & & $1(4)$ & & $4(7)$ & \\
\hline $\mathrm{SpO}_{2}[\%]$ & 105 & $86(92-97)$ & 21 & $96(92-97)$ & 26 & $96.5(93-98)$ & 58 & $95.0(91.0-97.0)$ & 0.20 \\
\hline $6 \mathrm{MWT} \triangle \mathrm{SpO}_{2}$ & 102 & $5(1-8)$ & 21 & $5(3-9)$ & 26 & $4.5(2-8)$ & 55 & $4.0(0.0-9.0)$ & 0.50 \\
\hline NT-proBNP [pg/ml] & 83 & 1079 (332-2592) & 22 & 1619.5 (422.9-4331.0) & 21 & 825 (219.9-1610.0) & 40 & $1121.0(360.0-2599.0)$ & 0.30 \\
\hline NT-proBNP risk group: & 83 & & 22 & & 21 & & 40 & & 0.54 \\
\hline Low & & $18(22)$ & & $4(18)$ & & $6(28.5)$ & & $8(20)$ & \\
\hline Intermediate & & $29(35)$ & & $6(27)$ & & $9(43)$ & & $14(35)$ & \\
\hline High & & $36(43)$ & & $12(55)$ & & $6(28.5)$ & & $18(45)$ & \\
\hline
\end{tabular}

Bold values denote statistical significance at the $p<0.05$ level

cGGO, centrilobular ground glass opacifications; pGGO, panlobular ground glass opacification; IQR, interquartile range; PFO, persistent foramen ovale; WHO FC, World Health Organisation functional class; DLCO, diffusion lung capacity for carbon monoxide; $6 \mathrm{MWD}, 6-\mathrm{min}$ walking test distance; $\mathrm{SpO}_{2}$, blood oxygen saturation; $\mathrm{NT}$, proBNP- N-terminal pro-brain natriuretic peptide. *For comparison between three HRCT patterns 
Table 2 Haemodynamic parameters and risk factors for the whole group and according to the HRCT pattern

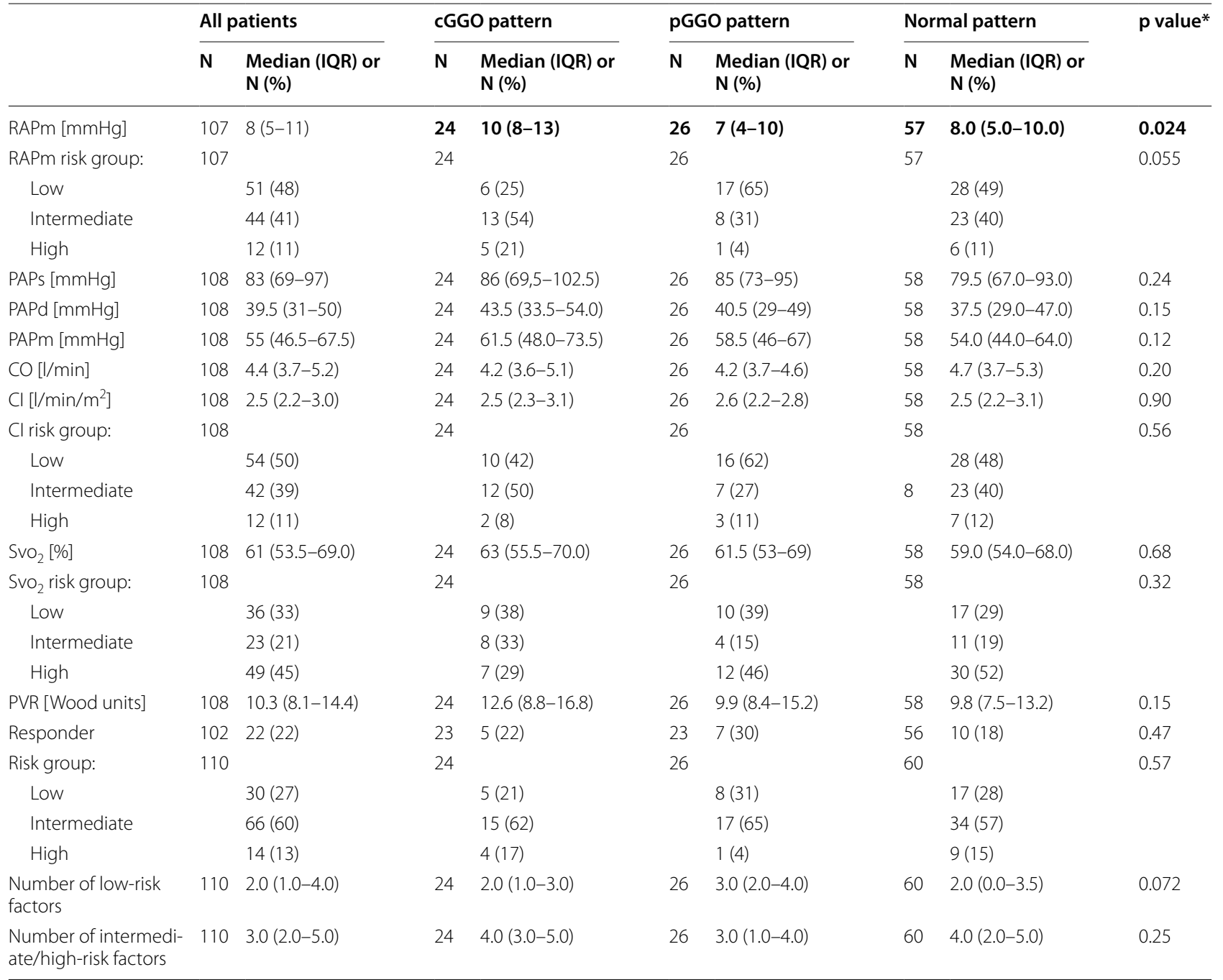

Bold values denote statistical significance at the $p<0.05$ level

cGGO, centrilobular ground glass opacifications; pGGO, panlobular ground glass opacification; IQR, interquartile range; RAPm, mean right atrial pressure; PAPs/d/m, systolic, diastolic and mean pulmonary artery pressures; $\mathrm{CO}$, cardiac output; $\mathrm{Cl}$, cardiac index; $\mathrm{SvO}_{2}$, mixed venous blood oxygen saturation; $\mathrm{PVR}$, pulmonary vascular resistance. *For comparison between three HRCT patterns

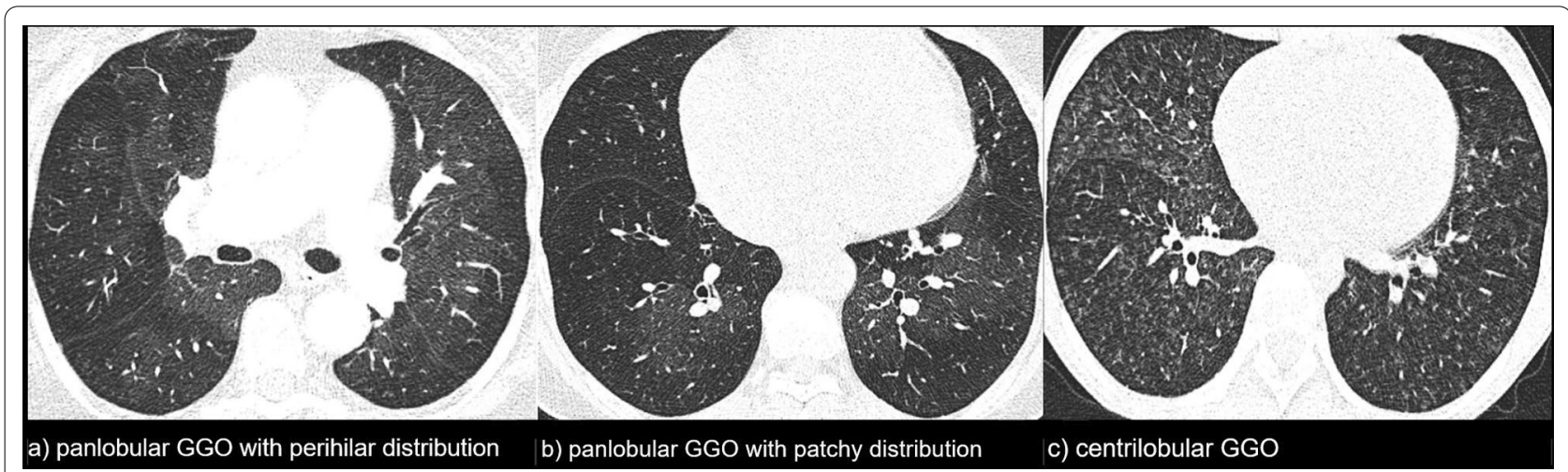

Fig. 1 Chest HRCT scans of IPAH patients showing different patterns of ground-glass opacifications (GGO) 
(26.6-49.6) vs $46.8(37.6-59.0)$ years, $\mathrm{p}=0.029$. The cGGO and pGGO groups had higher rates of patients with positive history of haemoptysis compared to the normal pattern group: $29 \%$ and $23 \%$ vs $9 \%, p=0.046$. There was no difference in WHO FC between the groups, but patients with the abnormal HRCT pattern had higher median value of 6MWD than patients with the normal pattern: 429 (380-484) vs 379 (298-450) $\mathrm{m}, \mathrm{p}=0.018$.

The distinctive features of the pGGO group were: (i) negative association with cigarette smoking: only $19 \%$ of these patients were ever-smokers vs $45 \%$ of the remaining patients, $p=0.019$, (ii) higher number of low-risk factors: $3.0(2.0-4.0)$ vs $2.0(0.0-3.0)$ in the remaining patients, $\mathrm{p}=0.024$. The distinctive feature of the cGGO group was higher median RAPm: 10.0 (8.0-13.0) vs 7.0 (4.0-10.0) $\mathrm{mmHg}$ in the remaining patients, $\mathrm{p}=0.008$.

There were no significant differences between the lung HRCT patterns in terms of presence of patent foramen ovale, oxygen saturation, DLCO\%pred, NT-proBNP, or haemodynamic parameters other than RAPm.

The results of logistic regressions are shown in Table 3. The independent predictors for pGGO were: higher number of low-risk factors, lower $\mathrm{CO}$, and positive history of haemoptysis. The independent predictors for cGGO were: younger age, higher RAPm, higher $\mathrm{Svo}_{2}$, and positive history of haemoptysis.

\section{Survival}

The median time of follow-up was 5.0 years, range $0.1-$ 22.1 years. During this time $73(66 \%)$ patients died (65 patients) or underwent LTx (8 patients), 26 (24\%) patients were still alive at the end of the study, and $11(10 \%)$ were lost to follow-up. The patients' LTx-free survival depending on the lung HRCT pattern is illustrated in Fig. 2 and summarised in Table 4 . The cGGO group had the lowest median LTx-free survival: 3.4 vs 6.2 and 5.8 years respectively for the pGGO and normal pattern groups. Within the first year occurred $50 \%, 15 \%$, and $0 \%$ of all the deaths/ LTx in the cGGO, pGGO and normal groups, respectively. $56 \%$ of unfavourable events in the cGGO group took place in first 2 years.

For $71 \%$ of the patients all six risk factors were documented, further $24 \%$ had 5 risk factors available, $5 \%$ of patients had 2-4 risk factors documented. $27 \%$ of the patients were in the low-risk group, $60 \%$ in the intermediate-risk group, and $13 \%$ in the high-risk group. The median number of low-risk factors was 2, $23 \%$ of the patients had no low-risk factors, $27 \%$ had at least 4 low-risk factors. There were no significant differences in distribution of the HRCT patterns in the risk groups, but pGGO pattern was associated with a higher number of low-risk predictors compared to other patterns - Table 2. One- and two-year LTx-free survival didn't differ significantly between the three risk groups $(\mathrm{p}=0.3$ and $\mathrm{p}=0.5$, respectively), or depending

Table 3 Univariate and multivariate logistic regression models for different patterns of ground glass opacification

\begin{tabular}{|c|c|c|c|c|}
\hline & \multicolumn{4}{|l|}{ cGGO } \\
\hline & \multicolumn{2}{|l|}{ Univariate } & \multicolumn{2}{|l|}{ Multivariate } \\
\hline & Odds ratio $(95 \% \mathrm{Cl})$ & p-value & Odds ratio $(95 \% \mathrm{Cl})$ & p-value \\
\hline Haemoptysis & $4.36(1.22-15.56)$ & 0.023 & 6.34 (1.39-28.95) & 0.015 \\
\hline Age $<40$ years & $4.22(1.55-11.45)$ & 0.005 & $4.56(1.41-14.47)$ & 0.01 \\
\hline $6 \mathrm{MWD}[\mathrm{m}]$ & $1.005(1.00007-1.01)$ & 0.047 & & \\
\hline RAPm $[\mathrm{mmHg}]$ & $1.11(1.005-1.23)$ & 0.04 & $1.21(1.05-1.38)$ & 0.017 \\
\hline \multirow[t]{4}{*}{$\mathrm{SvO}_{2}[\%]$} & $1.02(0.97-1.08)$ & 0.42 & $1.11(1.03-1.19)$ & 0.01 \\
\hline & \multicolumn{4}{|l|}{ pGGO } \\
\hline & \multicolumn{2}{|l|}{ Univariate } & \multicolumn{2}{|l|}{ Multivariate } \\
\hline & Odds ratio $(95 \% \mathrm{Cl})$ & p-value & Odds ratio $(95 \% \mathrm{Cl})$ & p-value \\
\hline Haemoptysis & $3.18(0.87-11.59)$ & 0.08 & $5.09(1.04-24.96)$ & 0.041 \\
\hline Female gender & $4.77(1.28-17.68)$ & 0.02 & & \\
\hline Cigarette smoking & $0.28(0.09-0.85)$ & 0.024 & & \\
\hline Number of low-risk factors & $1.33(1.02-1.73)$ & 0.036 & $2.32(1.46-3.69)$ & 0.0003 \\
\hline $\mathrm{CO}[\mathrm{l} / \mathrm{min}]$ & $0.68(0.43-1.09)$ & 0.11 & $0.31(0.14-0.66)$ & 0.002 \\
\hline
\end{tabular}

Bold values denote statistical significance at the $p<0.05$ level

cGGO, centrilobular ground glass opacification; pGGO, panlobular ground glass opacification; 6MWD, 6-min walking test distance; RAPm, mean right atrial pressure; $\mathrm{SvO}_{2}$, mixed venous blood oxygen saturation; $\mathrm{CO}$, cardiac output 


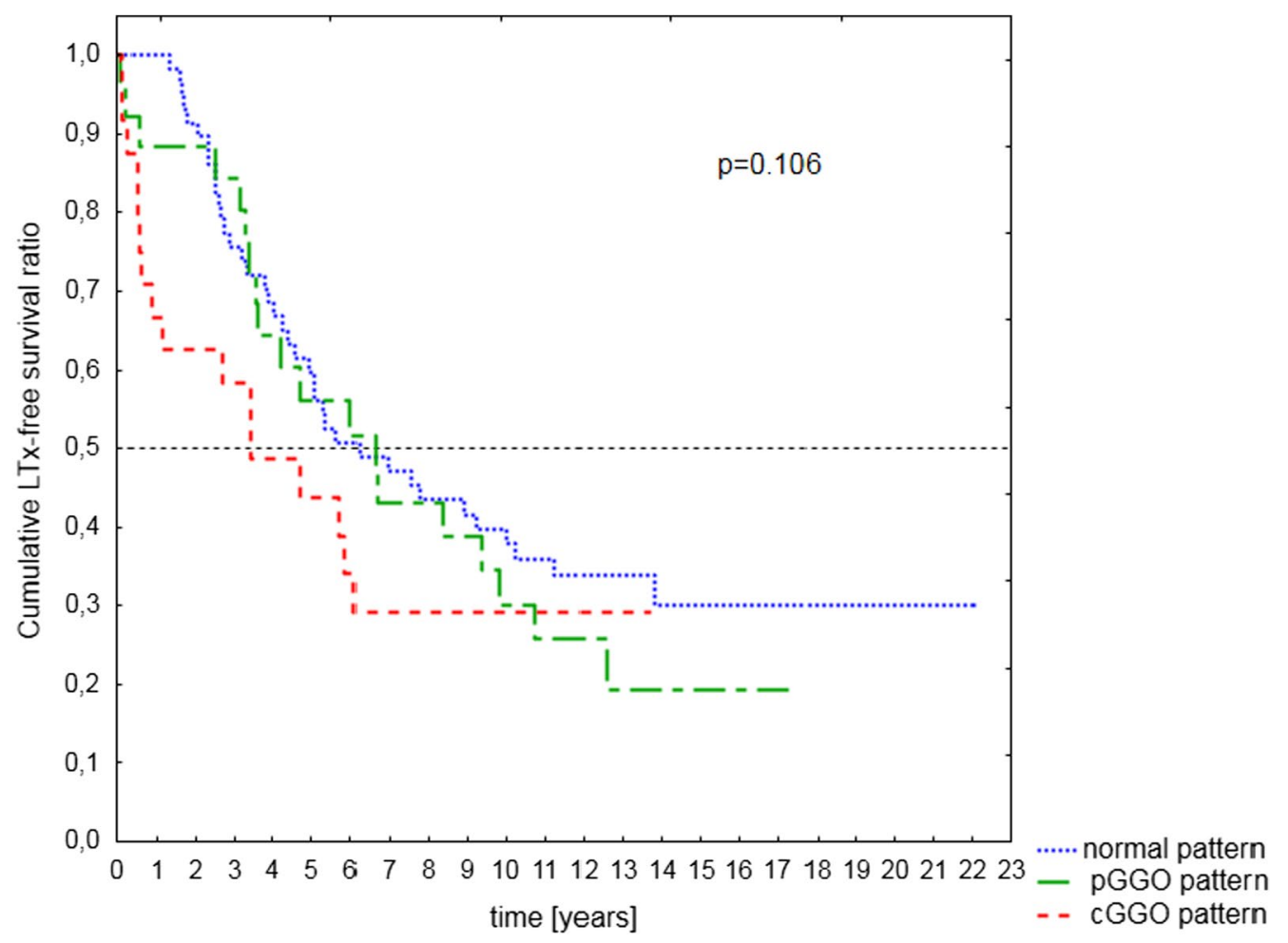

No. at risk $0-1-2-3-5-10$ years

normal $\quad \begin{array}{llllll}60 & 59 & 53 & 43 & 33 & 21\end{array}$

PGGO $\quad \begin{array}{llllll}26 & 22 & 22 & 21 & 13 & 7\end{array}$

$\begin{array}{lllllll}\text { cGGO } & 24 & 16 & 15 & 14 & 9 & 3\end{array}$

pGGO-panlobular ground glass opacifications; cGGO-centrilobular ground glass opacifications.

Fig. 2 Kaplan-Meier curves showing LTx-free survival depending on the lung HRCT pattern

Table 4 Survival rates for the whole group and according to chest HRCT patterns

\begin{tabular}{llllll}
\hline & \multicolumn{2}{l}{ Survival ratio $(\mathbf{9 5 \% C l )}[\%]$} & \multicolumn{2}{c}{ p-value* } \\
\cline { 2 - 5 } & Whole group & cGGG pattern & pGGO pattern & Normal pattern \\
\hline 1-year & $90.0(84.4-95.6)$ & $\mathbf{6 6 . 7}(\mathbf{4 7 . 8 - 8 5 . 5 )}$ & $\mathbf{8 8 . 5}(\mathbf{7 6 . 2 - 1 0 0 . 0 )}$ & $\mathbf{1 0 0 . 0}(\mathbf{9 4 . 9 - 1 0 0 . 0 )}$ & $\mathbf{0 . 0 0 0 0 2}$ \\
2-year & $84.4(77.6-91.2)$ & $\mathbf{6 2 . 5}(\mathbf{4 3 . 1 - 8 1 . 9 )}$ & $\mathbf{8 8 . 5}(\mathbf{7 6 . 2 - 1 0 0 . 0 )}$ & $\mathbf{9 1 . 4 ( 8 4 . 2 - 9 8 . 6 )}$ & $\mathbf{0 . 0 0 0 6}$ \\
3-year & $74.0(65.7-82.3)$ & $\mathbf{5 8 . 3 ( 3 8 . 6 - 7 8 . 1 )}$ & $\mathbf{8 4 . 4}(\mathbf{7 0 . 4 - 9 8 . 5 )}$ & $\mathbf{7 5 . 4 ( 6 4 . 5 - 8 6 . 7 )}$ & $\mathbf{0 . 0 2 4}$ \\
5-year & $55.4(45.9-64.9)$ & $43.8(23.2-64.3)$ & $56.0(365-75.6)$ & $61.5(48.9-74.6)$ & 0.09 \\
10-year & $34.9(25.5-44.2)$ & $29.2(9.9-48.4)$ & $30.2(11.7-48.6)$ & $39.7(26.9-52.6)$ & 0.12 \\
\hline
\end{tabular}

Bold values denote statistical significance at the $p<0.05$ level

cGGO, centrilobular ground glass opacifications; pGGO, panlobular ground glass opacification

* For comparison between cGGO and joined two remaining patterns

on number of low-risk factors $(\mathrm{p}=0.8$ and $\mathrm{p}=0.4$, respectively).

All three patients with cGGO and either lymphadenopathy or septal thickening had survival shorter than 1 year. The patient with pGGO, lymphadenopathy and septal thickening as well as all patients with normal pattern and lymphadenopathy survived longer than 2 years.

Significant independent predictors for negative outcome in the perspective of the whole follow-up were: intermediate/high risk group (HR 3.84, 95\% CI 
Table 5 Predictors of outcome in the 2-year perspective

\begin{tabular}{|c|c|c|c|c|}
\hline & \multicolumn{4}{|c|}{ DEATH or LTX In a 2-year perspective } \\
\hline & \multicolumn{2}{|l|}{ Univariate } & \multicolumn{2}{|l|}{ Multivariate } \\
\hline & Hazard ratio $(95 \% \mathrm{Cl})$ & p-value & Hazard ratio $(95 \% \mathrm{Cl})$ & p-value \\
\hline WHO FC 4 & $5.89(1.64-21.19)$ & 0.04 & & \\
\hline cGGO & $5.01(1.95-13.00)$ & 0.0009 & $6.22(1.37-28.18)$ & 0.018 \\
\hline DLCO [\%pred] & $0.96(0.93-0.99)$ & 0.001 & $0.95(0.92-0.98)$ & 0.005 \\
\hline NT-proBNP [pg/ml] & $1.0003(1.0001-1.0004)$ & 0.003 & & \\
\hline $6 \mathrm{MWT} \Delta \mathrm{SpO}_{2}[\%$ point $]$ & $1.05(0.999-1.1)$ & 0.05 & $1.13(1.04-1.22)$ & 0.004 \\
\hline
\end{tabular}

Bold values denote statistical significance at the $p<0.05$ level

WHO FC, World Health Organisation functional class; cGGO, centrilobular ground glass opacifications; DLCO, diffusion lung capacity for carbon monoxide; NT-proBNP, $\mathrm{N}$-terminal pro-brain natriuretic peptide; $6 \mathrm{MWT} \Delta \mathrm{SpO}_{2}$, change of blood oxygen saturation during 6-min walking test

Table 6 Predictors of outcome in the whole follow-up perspective

\begin{tabular}{|c|c|c|c|c|}
\hline & \multicolumn{4}{|c|}{ DEATH or LTX in in the whole follow-up perspective } \\
\hline & \multicolumn{2}{|l|}{ Univariate } & \multicolumn{2}{|l|}{ Multivariate } \\
\hline & Hazard ratio $(95 \% \mathrm{Cl})$ & P-value & Hazard ratio $(95 \% \mathrm{Cl})$ & P-value \\
\hline Male gender & $2.11(1.29-3.45)$ & 0.003 & & \\
\hline Cigarette smoking & $1.63(1.01-2.64)$ & 0.045 & & \\
\hline WHO FC 3-4 & $1.92(1.21-3.06)$ & 0.006 & & \\
\hline $6 \mathrm{MWD}[\mathrm{m}]$ & $0.9977(0.9957-0.9997)$ & 0.026 & & \\
\hline $\mathrm{SpO}_{2}[\%]$ & $0.91(0.87-0.96)$ & 0.0003 & & \\
\hline $6 \mathrm{MWT} \triangle \mathrm{SpO}_{2}$ & $1.04(1.01-1.06)$ & 0.009 & & \\
\hline DLCO [\%pred] & $0.97(0.96-0.99)$ & 0.0001 & $0.98(0.97-0.99)$ & 0.002 \\
\hline NT-proBNP[pg/ml] & $1.0002(1.0001-1.0004)$ & 0.0002 & & \\
\hline RAPm $[\mathrm{mmHg}]$ & $1.07(1.02-1.12)$ & 0.003 & & \\
\hline $\mathrm{CO}[\mathrm{l} / \mathrm{min}]$ & $0.77(0.62-0.97)$ & 0.026 & & \\
\hline $\mathrm{Cl}\left[\mathrm{l} / \mathrm{min} / \mathrm{m}^{2}\right]$ & $0.59(0.40-0.89)$ & 0.01 & & \\
\hline $\mathrm{SvO}_{2}[\%]$ & $0.97(0.95-0.99)$ & 0.013 & & \\
\hline Non-responder & $3.18(1.51-6.69)$ & 0.002 & & \\
\hline Number of low-risk factors & $0.76(0.66-0.88)$ & 0.0002 & & \\
\hline Intermediate/high risk group & $4.15(2.05-8.37)$ & 0.00007 & $3.84(1.71-8.59)$ & 0.001 \\
\hline
\end{tabular}

WHO FC, World Health Organisation functional class; 6MWD, 6-min walking test distance; $\mathrm{SpO}_{2}$, blood oxygen saturation; $6 \mathrm{MWT} \triangle \mathrm{SpO}{ }_{2}$, change of blood oxygen saturation during 6-min walking test; DLCO, diffusion lung capacity for carbon monoxide; NT-proBNP, N-terminal pro-brain natriuretic peptide; RAPm, mean right atrial pressure; $\mathrm{CO}$, cardiac output; $\mathrm{Cl}$, cardiac index; $\mathrm{SvO}_{2}$, mixed venous blood oxygen saturation

1.71-8.59) and DLCO\%pred (HR 0.98, 95\% CI 0.970.99). Independent predictors in the two-year perspective were: presence of cGGO (HR 6.22, 95 CI 1.37-28.18), DLCO\%pred (HR 0.95, 95\% CI 0.92-0.98), and decrease in oxygen saturation during 6-min walking test (HR 1.13, 95\% CI 1.04-1.22). Results of uni- and multivariate Cox regressions are shown in Tables 5 and 6.

\section{Discussion}

Chest HRCT plays an essential role in the workup of $\mathrm{PH}$ [1], and it is also common that the study is repeated during the disease course for various clinical reasons. The number of previous reports on lung HRCT appearance in IPAH is very limited $[3,6,11-17]$. We present the largest and most thorough analysis of the lung parenchyma attenuation inhomogeneity on HRCT scans of IPAH patients so far. We found mosaic attenuation in $46 \%$ of our patients: pGGO in 24\%, and cGGO in $22 \%$ of the patients. Rates were similar to previously reported [11, 12 ,17] and confirmed high prevalence of GGO in these patients population. In only one study, including $15 \mathrm{IPAH}$ patients, centrilobular pattern was more frequent than panlobular GGO pattern (80 vs $20 \%$, respectively) [6]. 
In our study, the groups of patients with centri- and panlobular GGO patterns shared some similarities that distinguished them from the patients with normal pattern: more frequent female gender, younger age, better 6MWD, and positive history of haemoptysis. We failed to find explanation for association of GGO with gender and age. Better 6MWD could be secondary to younger age of these patients. Haemoptysis is a recognised complication of IPAH associated with poor prognosis [33]. The prevalence of haemoptysis in our study group was $16 \%$. Tio et al. [34] reported haemoptysis in $4.8 \%$ of $228 \mathrm{I} / \mathrm{HPAH}$ patients, Montani et al. [3] in $8.3 \%$ of $24 \mathrm{I} / \mathrm{H} /$ anorexigeninduced $\mathrm{PAH}$, Ghigna et al. [35] in $57 \%$ of 44 patients who underwent LTx for I/HPAH. In the group reported by Tio et al. [34], patients with haemoptysis in anamnesis were younger, had earlier $\mathrm{PH}$ onset and more dynamic haemodynamic worsening than remaining patients. Data on lung imaging were not provided. Haemoptysis in PAH results from concomitant involvement of bronchial circulation and intrapulmonary bronchopulmonary anastomoses leading to pulmonary haemorrhage [36]. Alveolar haemorrhage is one of the explanations of GGO presence in PAH patients. Depending on bleeding extend and phase, it may appear either as cGGO or pGGO (patchy or confluent) [37]. In about $25 \%$ of patients with various forms of $\mathrm{PH}$, cholesterol granulomas with siderophages could be found in lung specimens $[15,38]$, and they were thought to be secondary to haemorrhage. There is no consensus whether cGGO seen on lung imaging studies correspond to cholesterol granulomas, small foci of haemorrhages, or extensive plexogenic arterial lesions $[15,38,39]$.

We found features distinctive for each GGO pattern group. The cGGO group was characterised by the highest RAPm, and that was in agreement with previous studies on smaller groups $[11,17]$. Independent predictors of cGGO were: younger age, positive history of haemoptysis, higher RAPm, and higher $\mathrm{Svo}_{2}$. The pGGO group had the lowest rate of cigarette smokers and the highest median number of low-risk factors. Independent predictors of pGGO were: positive history of haemoptysis, higher number of low-risk factors, and lower $\mathrm{CO}$.

We also demonstrated significant differences in shortterm survival rates between the groups. Presence of cGGO turned out to have a negative prognostic value for outcome in a 2-year perspective, with sixfold increase in death/LTx risk. The 1,2,3-year survival rates in the cGGO group were similar to those reported for high-risk group PAH patients in national and international registries [20, 22], although only $17 \%$ of cGGO patients were in the high-risk group at the baseline assessment. No prognostic value of pGGO compared to normal pattern was demonstrated. In our group, the prognostic value of
HRCT pattern was superior to ESC/ERS risk stratification approach in respect to a 2-year survival, but it lost its significance in favour of the latter in the long-term perspective. This could be explained by the high mortality in the cGGO group in the first years of follow-up, and small number of these patients staying in observation for longer than 6 years. It is also worth noting the significant prognostic value of DLCO\%pred both in short and long observation.

In the clinical context of PAH with GGO present on HRCT lung scans, it is of utmost importance to differentiate between IPAH and PAH with overt features of venous/capillaries (PVOD/PCH) involvement [1]. Survival in $\mathrm{PVOD} / \mathrm{PCH}$ is significantly worse than in other forms of $\mathrm{PAH}$, with reported mean LTx-free survival $1-2.5$ years $[3,4]$, and treatment with pulmonary vasodilators can cause pulmonary oedema [1]. A suspicion of $\mathrm{PVOD} / \mathrm{PCH}$ is an indication for LTx referral $[1,27,28]$. Although ultimate distinction can be made only on histopathologic or genetic basis, it is believed that diagnosis of PVOD/PCH may be established with high probability using a combination of non-invasive tests $[1,3,5,6]$. Diagnostic clues include very low DLCO, resting hypoxemia, severe exertional desaturation, and characteristic features on chest HRCT $[1,3,5]$. A triad of centrilobular ground-glass opacities, mediastinal lymphadenopathy, and smooth thickening of the interlobular septa is very suggestive for PVOD/PCH. Presence of at least two of the three features has a sensitivity of $75 \%$ and specificity of $85 \%$ for PVOD/PCH; normal chest HRCT doesn't exclude $\mathrm{PVOD} / \mathrm{PCH}$, though $[3,5]$. It's estimated that $3-12 \%$ of IPAH clinical diagnoses are indeed PVOD/ $\mathrm{PCH}$ [5]. It is possible that some patients in our cohort could have had PVOD/PCH. The radiological triad was seen in none of our patients, two patients with cGGO had lymphadenopathy, another one had septal thickening, one patient with pGGO had lymphadenopathy and septal thickening. According to the HRCT picture, 3.6\% of our patients had higher level of suspicion of PVOD/ $\mathrm{PCH}$. On the other hand, in patients with $\mathrm{I} / \mathrm{H} /$ anorexigen-induced $\mathrm{PAH}$, with no signs of $\mathrm{PVOD} / \mathrm{PCH}$ on lung pathologic evaluation, cGGO were seen in $23-28 \%$, septal thickening in $13-15 \%$, and lymphadenopathy in $8 \%$ $[3,6,15]$, and coexistence of at least two of these findings was present in $15 \%$ of the patients [3]; so specificity of cGGO for PVOD was only $73-77 \%[3,6]$. As lung biopsy is contraindicated in $\mathrm{PH}$, and access to genetic testing is limited, many PVOD/PCH diagnoses in reality are based on clinical observation. Applying a proper management is more important that making the specific diagnosis. General principles of referring patients for LTx are: (i) a 2-year predicted survival of $<50 \%$, and (ii) a high likelihood of post-transplant survival [27]. The results of 
our analysis indicate, that in patients with clinical diagnosis of IPAH with cGGO on the lung HRCT scans an early referral to LTx centres should be considered. With such approach, evaluation of the disease dynamic and response to medical treatment on one hand, and necessary LTx-related assessment on the other hand, could be done in parallel, improving timing for LTx listing.

Our research has shortcomings related to its retrospective character, possible selection bias, disregard of medical treatment in the analysis, and still small number of included patients. Nevertheless, it gives insights into different phenotypes of IPAH patients depending on lung HRCT pattern and proves independent significance of cGGO in predicting survival in a real-life patients cohort.

Further research is needed to elucidate many intriguing issues related to IPAH phenotype associated with GGO on lung HRCT, e.g. the histopathologic background of cGGO and pGGO, mutual dependence of causes and effects between GGO-related structures and PH course, relation between GGO and right ventricle performance assessed with echocardiography and/or cardiac magnetic resonance imaging, or effect of $\mathrm{PAH}$-specific treatment on GGO.

\section{Conclusions}

GGO are frequent findings on the lung HRCT scans of IPAH patients. Panlobular and centrilobular patterns of GGO are equally prevalent, but have different clinical significance. Presence of cGGO on HRCT scans of the lungs of IPAH patients has an add-on prognostic value for an outcome in a 2-year follow-up in reference to already well-established prognostic factors collected in the ESC/ERS multidimensional risk assessment tool, and could serve as an complementary element in making therapeutic decisions, e.g. the timing of referral for LTx assessment.

\footnotetext{
Abbreviations

PH: Pulmonary hypertension; PAPs/d/m: Systolic, diastolic, mean pulmonary artery pressures; RHC: Right heart catheterisation; PAH: Pulmonary arterial hypertension; PVR: Pulmonary vascular resistance; PAWP: Pulmonary artery wedge pressure; IPAH: Idiopathic pulmonary arterial hypertension; $\mathrm{HPAH}$ : Heritable pulmonary arterial hypertension; HIV: Human immunodeficiency virus; BMPR2: Bone morphogenetic protein receptor 2; PVOD: Pulmonary veno-occlusive disease; PCH: Pulmonary capillary haemangiomatosis; LTX: Lung transplantation; EIF1AK4: Eukaryotic translation initiation factor 2alpha kinase 4; DLCO: Lung diffusion capacity for carbon monoxide; HRCT: High resolution computed tomography; GGO: Ground-glass opacities; cGGO: Centrilobular ground-glass opacities; pGGO: Panlobular ground-glass opacities; ESC: European Society of Cardiology; ERS: European Respiratory Society; WHO FC: World Health Organisation functional class; NT-proBNP: N-terminal probrain natriuretic peptide; \%pred: Percent of predicted value; RAPm: Mean right atrial pressure; $\mathrm{CO}$ : Cardiac output; $\mathrm{Cl}$ : Cardiac index; $\mathrm{SvO}_{2}$ : Mixed venous blood oxygen saturation; IQR: Interquartile range; 6MWD: Six-minute walking test distance; HR: Hazard ratio; 95\% Cl: 95\% Confidence interval; PFO: Persistent foramen ovale; $\mathrm{SpO}_{2}$ : Blood oxygen saturation.
}

\section{Acknowledgements} Not applicable.

\section{Authors' contributions}

AK contributed to the conception and design of the work, data acquisition, statistical analysis and data interpretation, manuscript drafting. MS supervised the project and contributed to the conception and design of the work, data acquisition and interpretation, manuscript revision. BB was responsible for the radiological assessment. MK, AF, MF, MWM, SD contributed to data acquisition and manuscript revision. AT substantially revised the work for important intellectual content. All authors assisted in the editing and approval of the submitted paper. All authors read and approved the final manuscript.

\section{Funding}

This research did not receive any specific funding.

\section{Availability of data and materials}

The datasets used and analysed during the current study are available from the corresponding author on reasonable request.

\section{Declarations}

\section{Ethics approval and consent to participate}

No ethics committee approval or informed consent were required due to retrospective character of this study. It was conducted in agreement with the Declaration of Helsinki and the European General Data Protection Regulation.

\section{Consent for publication}

Not applicable.

\section{Competing interests}

AT reports personal financial support and fees from Actelion, AOP, Bayer, MSD and Pfizer outside the submitted work. The other authors report no conflict of interest associated with the content of this paper.

\section{Author details}

${ }^{1} 1$ st Department of Lung Diseases, National Tuberculosis and Lung Diseases Institute, Płocka 26, 01-138 Warsaw, Poland. ${ }^{2}$ Radiology Department, National Tuberculosis and Lung Diseases Institute, Warsaw, Poland. ${ }^{3}$ Department of Pulmonary Circulation and Thromboembolic Diseases, Medical Centre of Postgraduate Education, European Health Centre Otwock, Otwock, Poland. ${ }^{4}$ Department of Cardiology, Institute of Mother and Child, Warsaw, Poland.

Received: 20 June 2021 Accepted: 9 November 2021

Published online: 17 November 2021

\section{References}

1. Galie N, Humbert M, Vachiery JL, Gibbs S, Lang I, Torbicki, et al. ESC/ERS Guidelines for the diagnosis and treatment of pulmonary hypertension: the Joint Task Force for the Diagnosis and Treatment of Pulmonary Hypertension of the European Society of Cardiology (ESC) and the European Respiratory Society (ERS): endorsed by: Association for European Paediatric and Congenital Cardiology (AEPC), International Society for Heart and Lung Transplantation (ISHLT). Eur Respir J. 2015;2015(46):903-75.

2. Simonneau G, Montani D, Celermajer DS, Denton CP, Gazoulis MA, Krowka M, et al. Haemodynamic definitions and updated clinical classification of pulmonary hypertension. Eur Respir J. 2019;53:1801913.

3. Montani D, Achouh L, Dorfmüller P, Le Pavec J, Sztrymf B, Tchérakian C, et al. Pulmonary veno-occlusive disease: clinical, functional, radiologic, and hemodynamic characteristics and outcome of 24 cases confirmed by histology. Medicine (Baltimore). 2008:87:220-33.

4. Pérez Núñez M, Alonso Charterina S, Pérez-Olivares C, Revilla Ostolaza Y, Morales Ruiz R, Enguita Vallas AB, et al. Radiological findings in multidetector computed tomography (MDCT) of hereditary and sporadic pulmonary veno-occlusive disease: certainties and uncertainties. Diagnostics (Basel). 2021;11:141.

5. Montani D, Lau EM, Dorfmüller P, Girerd B, Jaïs $X$, Savale L, et al. Pulmonary veno-occlusive disease. Eur Respir J. 2016;47:1518-34. 
6. Resten A, Maitre S, Humbert M, Rabiller A, Sitbon O, Capron F, et al. Pulmonary hypertension: $\mathrm{CT}$ of the chest in pulmonary venoocclusive disease. Am J Roentgenol. 2004;183:65-70.

7. Hansell DM, Bankier AA, MacMahon H, McLoud TC, Müller NL, Remy J. Fleischner society: glossary of terms for thoracic imaging. Radiology. 2008;246:697-722.

8. Webb WR, Muller NL, Naidich DP. High-resolution CT of the lung. Lippincott Williams \& Wilkins: Philadelphia 2001; pp. 71-192.

9. Leung AN, Miller RR, Muller NL. Parenchymal opacification in chronic infiltrative lung diseases: CT-pathological correlation. Radiology. 1993;188:209-14

10. Foley RW, Kaneria N, Ross RVM, Suntharalingam J, Hudson BJ, Rodrigues $J C L$, et al. Computed tomography appearances of the lung parenchyma in pulmonary hypertension. Br J Radiol. 2020;94:20200830.

11. Kacprzak A, Szturmowicz M, Burakowska B, Fijałkowska A, Kurzyna M, Wieteska $\mathrm{M}$, et al. Abnormalities in high-resolution computed tomography of the lungs in patients with idiopathic pulmonary arterial hypertension - correlation with hemodynamic parameters and prognostic significance. Pneumonol Alergol Pol. 2009;77:23-30.

12. Rajaram S, Swift AJ, Condliffe R, Johns C, Elliot CA, Hill C, et al. CT features of pulmonary arterial hypertension and its major subtypes: a systematic CT evaluation of 292 patients from the ASPIRE Registry. Thorax. 2015;70:382-7.

13. Sherrick AD, Swensen SJ, Hartman TE. Mosaic pattern of lung attenuation on CT scans: frequency among patients with pulmonary artery hypertension of different causes. Am J Roentgenol. 1997;169:79-82.

14. Dufour B, Maître S, Humbert M, Capron F, Simonneau G, Musset D. High-resolution $\mathrm{CT}$ of the chest in four patients with pulmonary capillary hemangiomatosis or pulmonary venoocclusive disease. Am J Roentgenol. 1998;171:1321-4.

15. Nolan RL, McAdams HP, Sporn TA, Roggli VL, Tapson VF, Goodman PC Pulmonary cholesterol granulomas in patients with pulmonary artery hypertension: chest radiographic and CT findings. Am J Roentgenol. 1999;172:1317-9.

16. Resten A, Maitre S, Humbert M, Sitbon O, Capron F, Simoneau G, et al. Pulmonary arterial hypertension: thin-section CT predictors of epoprostenol therapy failure. Radiology. 2002;222:782-8

17. Szturmowicz M, Kacprzak A, Burakowska B, Skoczylas A, Bestry I, Kuś J, et al. Centrilobular nodules in high resolution computed tomography of the lung in IPAH patients - preliminary data concerning clinico-radiological correlates. Pneumonol Alergol Pol. 2016;84:265-70.

18. Benza RL, Miller DP, Barst RJ, Badesch DB, Frost AE, McGoon MD. An evaluation of long-term survival from time of diagnosis in pulmonary arterial hypertension from the REVEAL Registry. Chest. 2012;142:448-56.

19. Ling Y, Johnson MK, Kiely DG, Condliffe R, Elliot CA, Gibbs SR, et al. Changing demographics, epidemiology and survival of incident pulmonary arterial hypertension: results from the pulmonary hypertension registry of the United Kingdom and Ireland. Am J Respir Crit Care Med. 2012;186:790-6.

20. Hoeper MM, Kramer T, Pan Z, Eichstaedt CA, Spiesshoefer J, Benjamin N, et al. Mortality in pulmonary arterial hypertension: prediction by the 2015 European pulmonary hypertension guidelines risk stratification model. Eur Respir J. 2017:50:1700740.

21. Boucly A, Weatherald J, Savale L, Jaïs X, Cottin V, Prevot G, et al. Risk assessment, prognosis and guideline implementation in pulmonary arterial hypertension. Eur Respir J. 2017;50:1700889.

22. Kylhammar D, Kjellström B, Hjalmarsson C, Jansson K, Nisell M, Söderberg $\mathrm{S}$, et al. A comprehensive risk stratification at early follow-up determines prognosis in pulmonary arterial hypertension. Eur Heart J. 2018:39:4175-81.

23. Hoeper MM, Pausch C, Grünig E, Klose H, Staehler G, Huscher D, et al. Idiopathic pulmonary arterial hypertension phenotypes determined by cluster analysis from the COMPERA registry. J Heart Lung Transplant. 2020;39:1435-44

24. Kopeć G, Kurzyna M, Mroczek E, Chrzanowski Ł, Mularek-Kubzdela T, Skoczylas I, et al. Characterization of patients with pulmonary arterial hypertension: data from the Polish Registry of Pulmonary Hypertension (BNP-PL). J Clin Med. 2020;9:173.

25. Bisserier M, Pradhan N, Hadri L. Current and emerging therapeutic approaches to pulmonary hypertension. Rev Cardiovasc Med. 2020;21(2):163-79.

26. The International Society for Heart and Lung Transplantation. Adult Lung Transplantation Statistics, 2019, International Thoracic Organ Transplant (TTX) Registry Data. Slides. https://ishltregistries.org/downloadables/ slides/2019/lung_adult.pptx. Accessed 22 Apr 2021.

27. Weill D, Benden C, Corris PA, Dark JH, Davis RD, Keshavjee S, et al. A consensus document for the selection of lung transplant candidates: 2014_ an update from the Pulmonary Transplantation Council of the International Society for Heart and Lung Transplantation. J Heart Lung Transplant. 2015;34:1-15.

28. Hoeper MM, Benza RL, Corris P, de Perrot M, Fadel E, Keogh AM, et al. Intensive care, right ventricular support and lung transplantation in patients with pulmonary hypertension. Eur Respir J. 2019;53:1801906.

29. Benza RL, Gomberg-Maitland M, Miller DP, Frost A, Frantz RP, Foreman AJ, et al. The REVEAL Registry risk score calculator in patients newly diagnosed with pulmonary arterial hypertension. Chest. 2012;141:354-62.

30. de Perrot M, Granton JT, McRae K, Pierre AF, Singer LG, Waddell T, et al. Outcome of patients with pulmonary arterial hypertension referred for lung transplantation: a 14-year single-center experience. J Thorac Cardiovasc Surg. 2012;143:910-8.

31. Savale L, Le Pavec J, Mercier O, Mussot S, Jaïs X, Fabre D, et al. Impact of high-priority allocation on lung and heart-lung transplantation for pulmonary hypertension. Ann Thorac Surg. 2017:104:404-11.

32. Kurzyna M, Araszkiewicz A, Błaszczak P, Grabka M, Hawranek M, Kopeć G, et al. Summary of recommendations for the haemodynamic and angiographic assessment of the pulmonary circulation. Joint statement of the Polish Cardiac Society's Working Group on Pulmonary Circulation and Association of Cardiovascular Interventions. Kardiol Pol. 2015;73:63-8.

33. Żyłkowska J, Kurzyna M, Pietura R, Fijałkowska A, Florczyk M, Czajka C, et al. Recurrent hemoptysis: an emerging life-threatening complication in idiopathic pulmonary arterial hypertension. Chest. 2011;139:690-3.

34. Tio D, Leter E, Boerrigter B, Boonstra A, Vonk-Noordegraaf A, Bogaard HJ. Risk factors for hemoptysis in idiopathic and hereditary pulmonary arterial hypertension. PLOS ONE. 2013:8:e78132.

35. Ghigna M-R, Guignabert C, Montani D, Girerd B, Jaiis X, Savale L, et al. BMPR2 mutation status influences bronchial vascular changes in pulmonary arterial hypertension. Eur Respir J. 2016;48:1668-81.

36. Galambos C, Sims-Lucas S, Abman SH, Cool CD. Intrapulmonary bronchopulmonary anastomoses and plexiform lesions in idiopathic pulmonary arterial hypertension. Am J Respir Crit Care Med. 2016;193:574-6.

37. Cheah FK, Sheppard MN, Hansell DM. Computed tomography of diffuse pulmonary haemorrhage with pathological correlation. Clin Radiol. 1993:48:89-93.

38. Fischer EG, Marek JM, Morris A, Nashelsky MB. Cholesterol granulomas of the lungs associated with microangiopathic hemolytic anemia and thrombocytopenia in pulmonary hypertension. Arch Pathol Lab Med. 2000;124:1813-5.

39. Horton MR, Tuder RM. Primary pulmonary arterial hypertension presenting as diffuse micronodules on CT. Crit Rev Comput Tomogr. 2004:45:335e41.

\section{Publisher's Note}

Springer Nature remains neutral with regard to jurisdictional claims in published maps and institutional affiliations. 